\title{
Antioxidant Properties of the Ethyl Acetate Fraction of Intsia Palembanica (Merbau, Fabaceae)
}

\author{
Mizaton Hazizul Hasan*, Ibtisam Abdul Wahab and Aishah Adam \\ Department of Pharmacy, Universiti Teknologi MARA, Malaysia
}

*Corresponding author: Mizaton Hazizul Hasan, Department of Pharmacy,

Universiti Teknologi MARA, 42300 Puncak Alam, Selangor, Malaysia.

Received Date: November 12, 2019

Published Date: November 27, 2019

\begin{abstract}
Intsia palembanica (Fabaceae) is a tropical heartwood indigenous to Malaysia and countries of similar climates. The tree is commercially used for its timber. The aim of this study was to examine the antioxidant capacity of I. palembanica, reputedly rich in polyphenols, with a view to exploiting its sawdust as a source of antioxidants for the pharmaceutical and/or nutraceutical industries. The ethyl acetate fraction of I.palembanica was assessed for total phenolics and for antioxidant activity by several methods, viz, DPPH radical scavenging assay, ferrous chelating ability and inhibition of xanthine oxidase in purine metabolism. The results showed the ethyl acetate extract of I. palembanica to be a potent antioxidant, in vitro. Total phenolics in the extract was $668.2 \pm 58.2 \mu \mathrm{g}$ catechin equivalents/g. Median effective concentrations $\left(\mathrm{EC}_{50}\right)$ for $\mathrm{DPPH}_{\text {scavenging were }}$ $7.9 \pm 0.01 \mu \mathrm{g} / \mathrm{mL}$ and $4.5 \pm 0.02 \mu \mathrm{g} / \mathrm{mL}$ for the extract and standard antioxidant, trolox, respectively. $\mathrm{EC}_{50}$ for $\mathrm{Fe}^{2+}$ chelation was $19.95 \pm 2.37 \mathrm{mg} / \mathrm{mL}$ and $0.032 \pm 0.002 \mathrm{mg} / \mathrm{mL}$ for the extract and its comparator, EDTA. I. palembanica was very potent in inhibiting the production of uric acid with $\mathrm{IC}_{50}$ value of $6.3 \pm 2.5 \mu \mathrm{g} / \mathrm{mL}$ comparable to allopurinol which was $4.0 \pm 1.0 \mu \mathrm{g} / \mathrm{mL}$. Median inhibitory concentrations (IC ${ }_{50}$ ) for inhibition of tertbutylhydroperoxide was $1.26 \mu \mathrm{g} / \mathrm{mL}$, in comparison to the standard antioxidants, alpha-tocopherol acetate $\left(\mathrm{IC}_{50}=1.58 \mu \mathrm{g} / \mathrm{mL}\right)$ and trolox ( $\mathrm{IC}_{50}=3.98$ $\mu \mathrm{g} / \mathrm{mL}$ ). In summary, the ethyl acetate fraction of Intsia palembanica showed very potent antioxidant activity via various mechanisms. This holds promise for its use as a phytoantioxidant.
\end{abstract}

Keywords: Intsia palembanica; Antioxidant; Microsomal lipid peroxidation; $\mathrm{DPPH} ; \mathrm{Fe}^{2+}$; Xanthine oxidase

\section{Introduction}

Plants are playing an important role in maintaining human health and improving the quality of life. Since their ancestors, many people from developing countries have been using traditionally plant-derived products, especially from forests, to treat human and livestock diseases Rao et al. A few countries such as China, India, Thailand, Sri Lanka, Cuba, and a few others have sanctioned the official use of traditional of medicine in their healthcare programs Prajapati et al. [1]. Modern pharmacopoeia currently has about $25 \%$ of drugs obtained from plants and several others are synthetic analogues built on prototype compounds isolated from plants [2]. A study has been done on the Australian tropical forests on the pharmacological activities of 90 species of plants representing 19 families. 53 of the plant species examined indicated phytomedicinal potential for further investigation [3]. Most of the pharmacological effects of these plants are contributed to the presence of phenolic constituents which are broadly distributed in the plant kingdom. Many studies have found strong relationship between the presence of phenolic constituents (flavanoids, phenolic acids, diterpenes and tannins) in plants and their high antioxidant activities (Rice-Evans et al., 1995; Velioglu et al., 1998; Nakachi et al., 2000; Conforti et al., 2009). Some epidemiological studies have suggested an association between the consumption of phenolic-rich fruits and vegetables or beverages and the prevention of cardiovascular diseases and cancer [4-7]. These pathological conditions are connected with excessive free radical production that could also lead to various serious diseases such as neurodegenerative disorders, atherosclerosis, cataracts and inflammation (Aruoma, 1998; Liu and Stern, 1998; Babior and Andreoli 2000). Iron can induce lipid peroxidation by the Fenton reaction, and also increase lipid peroxidation by highly reactive hydroxyl radical generated from biological systems (Liochev, 1999). Numerous studies confirmed the ability of plant polyphenols to scavenge free radicals and chelate metal ions, established their potential act as chain-breaking antioxidants [8].

Intsia palembanica (Fabaceae or Leguminosae) is an indigenous heartwood which has been shown to be rich in polyphenols [9]. The leaf, root and bark of Intsia palembanica are used in traditional 
medicine for the treatment of urinary infections, rheumatoid arthritis and dysentry [10-12]. The potential value of Intsia palembanica as an antioxidant lies in its polyphenolic content, which include the stilbene, piceatannol and the flavonoids, myricetin and robinetin [9]. The presence of tannin, which is an astringent polyphenolic compound, and other polypenols such as flavonoids in some Chinese and Congolese medicinal plants have been reported to have significant effect in treating dysentery, diarrhea, bleedings and various skin inflictions $[13,14]$. It is well known that tannins and flavonoids have anti-inflammatory, antidiarrheic and wound healing properties [15-17]. Therefore, many studies have been carried out on medicinal plants to investigate the presence and activities of polyphenols and relate to their antioxidant activities to support their traditional claims [18-24]. This study was designed to determine the antioxidant potential of I. palembanica by studying its effects on different antioxidant assays. The abilities of $I$. palembanica fraction to scavenge DPPH radical ( $\mathrm{DPPH}^{\circ}$ ) and chelate metal ions were examined. Inhibition of malondialdehyde (MDA) formation in hydroperoxide-initiated lipid peroxidation in rat liver microsomes was also identified.

\section{Materials and Methods}

\section{Plant material}

Wood sample was supplied by Forest Research Institute Malaysia, Kepong from its repository of timber wood samples. Confirmation of the identity was obtained from microscopical examination of a fragment of the sample.

\section{Extraction and isolation}

The extraction of the heartwood was adapted from [25]. The planks of Intsia palembanica were ground into powder and delipidated by hexane (maceration for 20 hours, lixiviation with fresh solvent for 4 hours). After removal of hexane, the samples were extracted by methanol (maceration for 20 hours, lixiviation with fresh solvent for 8 hours). The combined methanolic extracts were evaporated to dryness. The resulting residue was then partitioned between water and ethyl acetate. The ethyl acetate solution was dried under reduced pressure to yield the ethyl acetate fraction. Intsia palembanica ethyl acetate fraction was then subjected to a primary fractionation on Sephadex ${ }^{\circledR}$ LH-20 (load 1\%) using a Büchi medium pressure liquid chromatography system, operated at 7 bars. A gradient mobile phase consisting of $\mathrm{MeOH} / \mathrm{H}_{2} \mathrm{O}$ 50:50 to $100 \% \mathrm{MeOH}$ were used. The separation was monitored by recording the ultraviolet (UV) absorbance at two wavelengths (283 and $340 \mathrm{~nm}$ ). This pre-fractionation yielded 5 fractions.

\section{Chemicals}

Glutathione reductase, thiobarbituric acid, trichloroacetic acid, 1,1-diphenyl-2-picryl-hydrazil, EDTA, quercetin, trolox and ferrozine were obtained from Sigma (St. Louis, USA).

\section{Animals}

Male albino Sprague-Dawley rats (180-250 g) were obtained from the Universiti Kebangsaan Malaysia, Malaysia animal house.
They were maintained on standard animal pellets and water ad libitum. Permission and approval for animal studies were obtained from the Animal Ethics Committee, Universiti Kebangsaan Malaysia. The rat was killed, and liver was excised for the preparation of liver microsomal system. A total number of 6 rats were used in this study.

\section{Phytochemical screening}

Extract $(20 \mathrm{mg}$ ) was dissolved in $10 \mathrm{~mL}$ of methanol for 10 min and filtered. Filtrate $(1000 \mu \mathrm{L})$ was transferred into two test tubes and a few drops of concentrated HCL were added. To test for flavonoids, the first tube was shaken for $2 \mathrm{~min}$, and a piece of magnesium powder was then added. A positive result was indicated by a change in colour of the sample to red. The second tube was shaken for $2 \mathrm{~min}$ and a few drops of Mayer's reagent were added. Formation of a yellow-cream precipitate showed presence of alkaloids. To detect presence of saponins in extract, $500 \mathrm{mg}$ of extract was mixed with $5 \mathrm{~mL}$ distilled water in a test tube which was then shaken vigorously. Formation of a stable froth for at least 15 min indicated presence of saponins.

\section{Determination of total phenolic content}

Total phenolic content in the Intsia palembanica ethyl acetate fraction with Folin-Ciocalteu reagent, according to the method of Singleton \& Rossi (1965) using catechin as a standard. Briefly, saturated sodium carbonate $(0.5 \mathrm{~mL})$ were added to $0.5 \mathrm{~mL}$ of the prepared sample and left for $15 \mathrm{~min}$. Then, $0.5 \mathrm{~mL}$ Folin-Ciocalteu reagent ( $1: 3 \mathrm{v} / \mathrm{v}$ diluted with water) were added and incubated for another $35 \mathrm{~min}$. The absorbances of the samples were measured at $725 \mathrm{~nm}$ by spectrophotometer (Amersham 2100Pro, UK). All samples were analyzed in triplicates. The results were expressed as microgrammes of catechin equivalents per $\mathrm{g}$ dry weight extract by using an equation that was obtained from the standard catechin graph.

\section{DPPH scavenging activity}

The free radical scavenging activity of Intsia palembanica extract was measured by 1,1-diphenyl-2-picryl-hydrazil radical (DPPH*) using a modified method described by [26]. Briefly, 0.1 mM solution of $\mathrm{DPPH}^{*}$ in ethanol was prepared. $10 \mathrm{~mL}$ of the Intsia palembanica fraction in methanol at different concentrations (0.01$1 \mathrm{mg} / \mathrm{mL}$ ) was added to $990 \mathrm{~mL}$ of the solution. The mixture was shaken vigorously and allowed to stand at room temperature for $10 \mathrm{~min}$. Then, the spectrophotometric measurement was taken at absorbance $517 \mathrm{~nm}$ (Amersham 2100Pro, UK). Lower absorbance of the reaction mixture indicated higher free radical scavenging activity.

The percentage of $\mathrm{DPPH}^{*}$ scavenging effect was calculated using the following equation:

$$
\text { DPPH' scavenging effect }(\%)=A_{1} / A_{0} \times 100
$$

Where $A_{0}$ was the absorbance of the control reaction and $A_{1}$ was the absorbance in the presence of the standard sample or the $I$. palembanica fraction. 


\section{Ferrous ion chelating activity}

Ferrous ion chelating (FIC) activity was measured by inhibition the formation of iron (II)-ferrozine complex after treatment with $\mathrm{Fe}^{2+}$ [27]. Briefly, the reaction mixture contained $500 \mu \mathrm{L}$ samples or EDTA, $100 \mu \mathrm{L}$ of $0.6 \mathrm{mM} \mathrm{FeCl}_{2}$ and $900 \mu \mathrm{L}$ of methanol. Methanol was used as a blank. EDTA was used as a standard reference. Intsia palembanica was dissolved in methanol. The mixture was shaken vigorously and left at room temperature for $5 \mathrm{~min}$. After that, 100 $\mu \mathrm{L}$ of $5 \mathrm{mM}$ ferrozine in methanol was added, mixed and incubated for 10 mins at room temperature to complex the residual $\mathrm{Fe}^{2+}$. The purple colour solution which formed indicated the formation of ferrous-ferrozine complex and spectrophotometric measurements were carried out at $562 \mathrm{~nm}$ against the methanol blank.

The percentage of chelating agent will be calculated by using the following equation:

$$
\text { Chelating effect }(\%)=\left[\left(1-A_{1}\right) / A_{0}\right] \times 100
$$

Where $\mathrm{A}_{0}$ was the absorbance of the control reaction and $\mathrm{A}_{1}$ was the absorbance in the presence of the standard sample or the Intsia palembanica fraction. The chelating effect (\%) was plotted against the log concentration of the sample in $\mathrm{mg} / \mathrm{mL}$ of reaction mixture. The effective concentration that produced $50 \%$ scavenging effect value $\left(\mathrm{EC}_{50}\right)$ was obtained from the graph (\% chelating effect vs. log concentration).

\section{Xanthine oxidase inhibitory assay}

Xanthine oxidase inhibitory (XOI) activity was estimated by the formation of uric acid from xanthine-xanthine oxidase system under aerobic condition (Kong et al., 2000). Briefly, the reaction mixture containing $400 \mu \mathrm{l}$ of $200 \mathrm{mM}$ phosphate buffer ( $\mathrm{pH} 7.5$ ), $200 \mu \mathrm{l}$ of $0.6 \mathrm{mM}$ xanthine, $20 \mu \mathrm{l}$ of sample solution, $180 \mu \mathrm{l}$ of distilled water and $200 \mu \mathrm{l}$ of $1 \mathrm{u}$ xanthine oxidase enzyme were directly mixed in the cuvette. Samples were weighed and serial dilution was done to make six different concentrations which were $10,1,0.1,0.01,0.001$ and $0.0001 \mathrm{mg} / \mathrm{ml}$ (final concentration in the cuvette). Allopurinol that was the standard was dissolved in the DMSO and Intsia palembanica was dissolved in methanol. After that, all working reagents and enzyme in cuvette were mixed thoroughly. The mixture was incubated for 1 minute at room temperature. The inhibitory activity of xanthine oxidase was assessed by measuring the absorption increment at $295 \mathrm{~nm}$ at room temperature which indicating the formation of uric acid from xanthine.

The inhibition of xanthine oxidase was measured as \% of inhibition $=(1-\beta / \alpha) \times 100$, where $\alpha$ is the change in absorbance per minute without the sample ( $\Delta$ Ablank with enzyme - $\Delta$ Ablank without enzyme), and $\beta$ is the change in absorbance per minute with the sample ( $\Delta$ Atest with enzyme - $\Delta$ Atest without enzyme). The inhibitory effect (\%) was plotted against the log concentration of test material in $\mu \mathrm{g} / \mathrm{mL}$ of reaction mixture. From the graph, effective concentration that produces $50 \%$ inhibition effect value $\left(\mathrm{IC}_{50}\right)$ was determined.

\section{Liver microsomal system}

Rat liver microsomes were prepared by tissue homogenization with 4 volumes of ice-cold $0.15 \mathrm{M} \mathrm{KCl}$. Microsomal fractions were isolated in phosphate buffer, $\mathrm{pH}$ 7.4, by removal of the nuclear fraction at $3000 \mathrm{~g}$ for $10 \mathrm{~min}$, removal of the mitochondrial fraction at 10,000 $\mathrm{g}$ for $30 \mathrm{~min}$ and sedimentation at $105,000 \mathrm{~g}$ for $60 \mathrm{~min}$. Fractions were washed twice in the buffer and the microsome pellets were stored at $-80^{\circ} \mathrm{C}$ for a maximum of one month.

\section{Hydroperoxide-initiated lipid peroxidation}

The inhibitory effect on lipid peroxidation was assessed by measuring TBARS by a modified method of [28], mainly constituted by MDA. Microsomal fractions were diluted with $0.05 \mathrm{M}$ Tris-HCI, pH 7.4, containing KC1 $(0.15 \mathrm{M})$. The final protein concentration in the incubation mixture was determined by the Lowry method and amounted to $0.75 \mathrm{mg} / \mathrm{mL}$. The mixture was then preincubated in a shaking waterbath at $37^{\circ} \mathrm{C}$ for $10 \mathrm{~min}$ with different concentrations of the Intsia palembanica fraction. Lipid peroxidation was initiated with $3 \mathrm{mM}$ tert-butyl-hydroperoxide. After incubating the samples for $10 \mathrm{~min}, 0.2 \mathrm{~mL}$ of the incubation mixture were taken out immediately into a test tube and $0.5 \mathrm{~mL} 20 \%$ trichloroacetic acid (TCA) was added to stop the lipid peroxidation reaction. $0.75 \mathrm{~mL}$ $0.67 \%$ thiobarbituric acid (TBA) was added in the mixture followed by $10 \mathrm{~min}$ incubation in $95^{\circ} \mathrm{C}$ waterbath. $2 \mathrm{~mL}$ of $\mathrm{n}$-butanol was added and vortexed vigourously for $3 \mathrm{~min}$. After centrifugation at $3000 \mathrm{~g}$ for $10 \mathrm{~min}$, the separated butanol layer was measured at Ex 515 nm, Em 553 nm using spectrofluorometer (Perkin-Elmer, UK). Inhibition of lipid peroxidation was expressed as a percentage, and the $\mathrm{IC}_{50}$ was obtained from the inhibition curve.

\section{Statistical analysis}

Data were expressed as means \pm S.D. Statistical analysis was performed using Student's $t$-test or by one-way analysis of variance, followed by post-hoc test for multiple comparisons of unpaired data. A value of $p<0.05$ was considered significant.

\section{Results and Discussion}

\section{HPLC analysis of the extract}

For the 5 fractions, methods P1 to P5 were respectively developed Table 1. The compounds are identified as follows. Fraction I gave compound $\underline{3}$, robinetinidol $\left(t_{R}=23.5 \mathrm{~min}\right)$ after purification with prep HPLC, isocratically at $12 \%$ MeCN. Meanwhile, fraction II yielded dihydrorobinetin $\underline{4}$. Fraction III yielded two isomers of ampelopsin: $\underline{5},(2 R, 3 S)$ - and $(2 R, 3 R)$-ampelopsin $\underline{6}$ were found to be in ratio of $80: 20\left(\mathrm{t}_{\mathrm{R}}=9.7\right.$ and $11.1 \mathrm{~min}$, respectively). These two compounds were examined by the same analytical HPLC procedure (MeCN: $\left.\mathrm{H}_{2} \mathrm{O}=25: 75\right)$. $\mathrm{t}_{\mathrm{R}}$ were found to be 6.7 and $6.3 \mathrm{~min}$ for $(2 R, 3 S)$ - and $(2 R, 3 R)$-ampelopsin, respectively. Robinetin 1 was separated as a single constituent from fraction IV. Finally, myricetin $\underline{2}$ was eluted from fraction V. It was found out that the composition of I. palembanica was much more complex than it had been previously reported [9]. Robinetin and myricetin have been earlier isolated from I. palembanica, while compounds 
robinetinidol, dihydrorobinetin and the two isomers of ampelopsin [ $(2 R, 3 S)$ - and $(2 R, 3 R)$-ampelopsin] are new compounds being identified from this species (Figure 1). These polyphenols have been found to possess anticancer, antimutagenic, antibacterial, antiobesity, antidiabetic activities [29-31] (Table 1).

Table 1: HPLC conditions for the fractions and the compounds from I. palembanica.

\begin{tabular}{|c|c|c|c|c|c|}
\hline Fractions & Preparative conditions $\mathrm{s}^{\mathrm{a}}$ & Compound & Analytical conditions ${ }^{\mathrm{a}}$ & tR, min & Weight (mg) \\
\hline I & $\mathrm{P} 1: \mathrm{MeCN} / \mathrm{H}_{2} \mathrm{O}: 12: 88,25 \mathrm{~min}$ & $\underline{3}$ & $\mathrm{~A} 1: \mathrm{MeCN} / \mathrm{H}_{2} \mathrm{O}: 25: 75$ & 6.5 & 17 \\
\hline II & $\mathrm{P} 2: \mathrm{MeCN} / \mathrm{H}_{2} \mathrm{O}: 12: 88,20 \mathrm{~min}$ & $\underline{4}$ & A2: $\mathrm{MeCN} / \mathrm{H}_{2} \mathrm{O}: 20: 80$ & 4.8 & 33 \\
\hline \multirow[t]{2}{*}{ III } & P3: $\mathrm{MeCN} / \mathrm{H}_{2} \mathrm{O}: 20: 80,15 \mathrm{~min}$ & $\underline{5}$ & A3: $\mathrm{MeCN} / \mathrm{H}_{2} \mathrm{O}: 25: 75$ & 6.3 & 41 \\
\hline & & $\underline{6}$ & & 6.8 & 10.2 \\
\hline IV & P4: $\mathrm{MeCN} / \mathrm{H}_{2} \mathrm{O}: 23.5: 76.5,30 \mathrm{~min}$ & $\underline{2}$ & $\mathrm{~A} 4: \mathrm{MeCN} / \mathrm{H}_{2} \mathrm{O}: 30: 70$ & 6 & 64 \\
\hline $\mathrm{V}$ & P5: $\mathrm{MeCN} / \mathrm{H}_{2} \mathrm{O}: 23: 77,15 \mathrm{~min}$ & $\underline{1}$ & & 9 & 52 \\
\hline
\end{tabular}

${ }^{a}$ All solvents were added with $0.01 \%$ TFA.

\section{Phytochemical screening}

Qualitative analysis of I. palembanica extract showed high amounts of flavonoids, a polyphenol group, in EtOAc extract (Table 2).

Table 2: Qualitative analysis of phytochemicals of Intsia palembanica extract.

\begin{tabular}{|c|c|}
\hline Phytochemical test & Score \\
\hline Flavonoids & +++ \\
\hline Alkaloids & +++ \\
\hline Saponins & ++ \\
\hline
\end{tabular}

Remarks: +++: High concentration; ++: moderate concentration; +: less concentration; -: absent

\section{Antioxidant activities}

Amounts of phenolic of Intsia palembanica extract was found to be $668.2 \pm 58.2 \mu \mathrm{g}$ catechin equivalents/mg dry weight. When this amount is compared to those found in other studies in the literature, polyphenols seemed to have an important role in stabilizing lipid oxidation and is associated with the antioxidant activity Yen et al. [32]. About $0.7 \mathrm{mg}$ of catechin equivalents of phenol were present in $1 \mathrm{mg}$ of the I. palembanica ethyl acetate extract which may contribute directly to the antioxidative action shown by the extract (Duh et al., 1999). It has been suggested that up to $1 \mathrm{~g}$ of polyphenols consumed daily from diet rich in fruits and vegetables have the ability to inhibit mutagenesis and carcinogenesis in humans [33]. The findings indicated that EtOAc was the best solvent to be used for extracting phenolic components from plants. Similar findings were reported by Sim, et al. (2010), Al-Juhaimi, et al. (2013) and Kusirisin, et al. (2009). The reduction capability of $\mathrm{DPPH}^{*}$ was determined by the decrease in its absorbance at 517 $\mathrm{nm}$ induced by antioxidants. The decrease in absorbance of DPPH caused by antioxidants is due to the reaction between antioxidant molecules and radical progresses, which results in the scavenging of the radical by hydrogen donation. It is visually noticeable as a discolouration from purple to yellow. Therefore, $\mathrm{DPPH}^{\bullet}$ is usually used as a substrate to evaluate antioxidative activity of antioxidants. Trolox was used as standard. The scavenging effect of I. palembanica extract and standards on the DPPH ${ }^{\bullet}$ decreased in the order of Trolox and I. palembanica extract with the $\mathrm{EC}_{50}$ of $4.5 \pm 0.02 \mu \mathrm{g} / \mathrm{mL}$ and $7.9 \pm 0.01 \mu \mathrm{g} / \mathrm{mL}$, respectively. The effects of I. palembanica extract reached a plateau at $59.1 \%$ as compared to Trolox which reached the maximum at $74.9 \%$. These results indicated that I. palembanica extract has a noticeable effect on scavenging free radical and the free radical scavenging activity also increased with increasing concentration. This effect may be due to the polyphenolic content in the Intsia palembanica extract which include the piceatannol, resveratrol, myricetin and robinetin [9] and the new isolated compounds, robinetinidol, dihydrorobinetin and the two isomers of ampelopsin [(2R, 3S)- and $(2 R, 3 R)$-ampelopsin] (Figure 1).

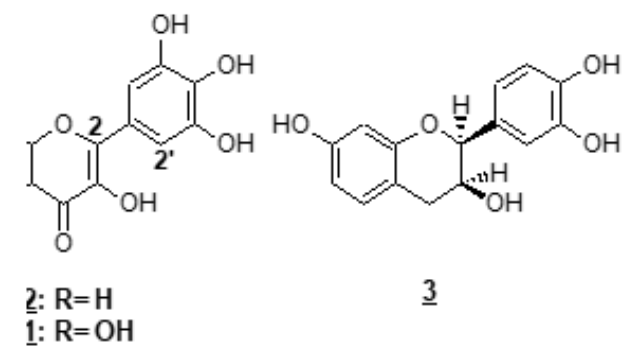

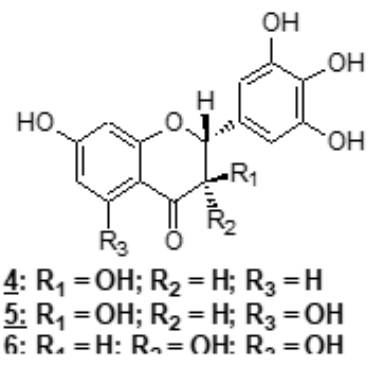

Figure 1: Phenolics isolated from Intsia palembanica.

EDTA was used as a standard reference for measuring the iron chelating activity. EDTA is a potent chelating agent of metals. When compared to the test compounds, EDTA showed the best chelating activity because the effect can be seen even at low concentrations.
The effective concentration that produced $50 \%$ effect value $\left(\mathrm{EC}_{50}\right)$ of EDTA was $0.032 \pm 0.002 \mathrm{mg} / \mathrm{mL}$ (Table 3). However, the $\mathrm{EC}_{50}$ value of of I. palembanica was $19.95 \pm 2.37 \mathrm{mg} / \mathrm{mL}$ (Table 3). EDTA was 600 times more potent than I. palembanica in chelating iron but, 
has more potential than trolox and ascorbic acid. I. palembanica exhibited the high xanthine oxidase inhibitory activity with $\mathrm{IC}_{50}$ value of $6.3 \pm 2.5 \mu \mathrm{g} / \mathrm{ml}$ (Table 3). Allopurinol, drug used for the treatment of gout, was used as the standard reference. The $\mathrm{IC}_{50}$ value was $4.0 \pm 1.0 \mu \mathrm{g} / \mathrm{ml}$ (Table 3) and this $\mathrm{IC}_{50}$ value of allopurinol was comparable to a study done by Umamaheswari et al. (2007), 6.75 $\mu \mathrm{g} / \mathrm{ml}$. This suggests that the I. palembanica inhibitory effect was as potent as allopurinol. Xanthine is a substrate of xanthine oxidase.
Xanthine oxidase plays an important role in converting xanthine to uric acid and superoxide anion radical (Figure 2). By adding test compounds in the reaction mixture, the enzyme can be inhibited and consequently lead to a decrease in the production of uric acid and superoxide anion radicals. The higher the concentrations of the tested compounds, the more xanthine oxidase enzymes were inhibited. Nonetheless, the inhibitory effect was saturable at high concentration of the test compounds (Figure 2) (Table 3).

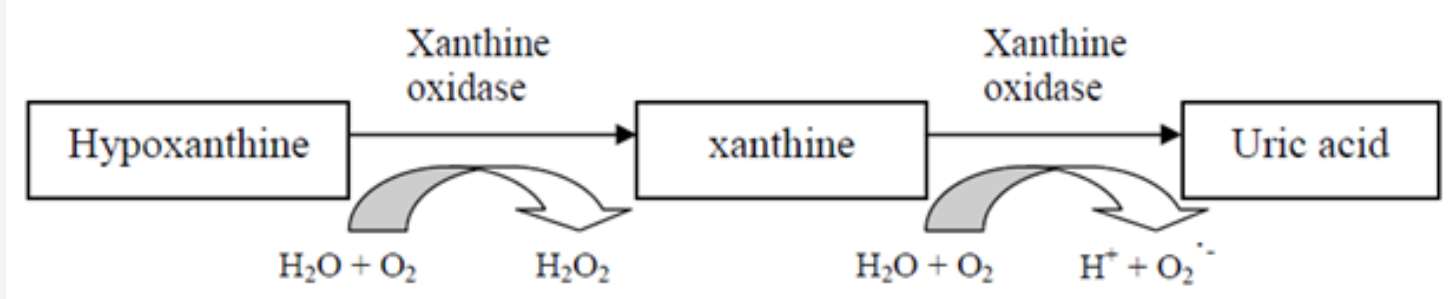

Figure 2: Formation of uric acid.

Table 3: Antioxidant activities of Intsia palembanica extract. Values are mean \pm SD $(n=3)$.

\begin{tabular}{|c|c|c|c|c|}
\hline & $m g C E / g$ extract & \multicolumn{2}{|c|}{$E C_{50}(\mu g / m L)$} & FIC assay \\
\hline Intsia palembanica & TPC & DPPH assay & $199 / m L)$ \\
\hline Trolox & $668.2 \pm 58.2$ & $7.9 \pm 0.01$ & $6.0 \pm 23.7$ \\
\hline EDTA & - & $4.5 \pm 0.02$ & - \\
\hline Allopurinol & - & - & - & - \\
\hline
\end{tabular}

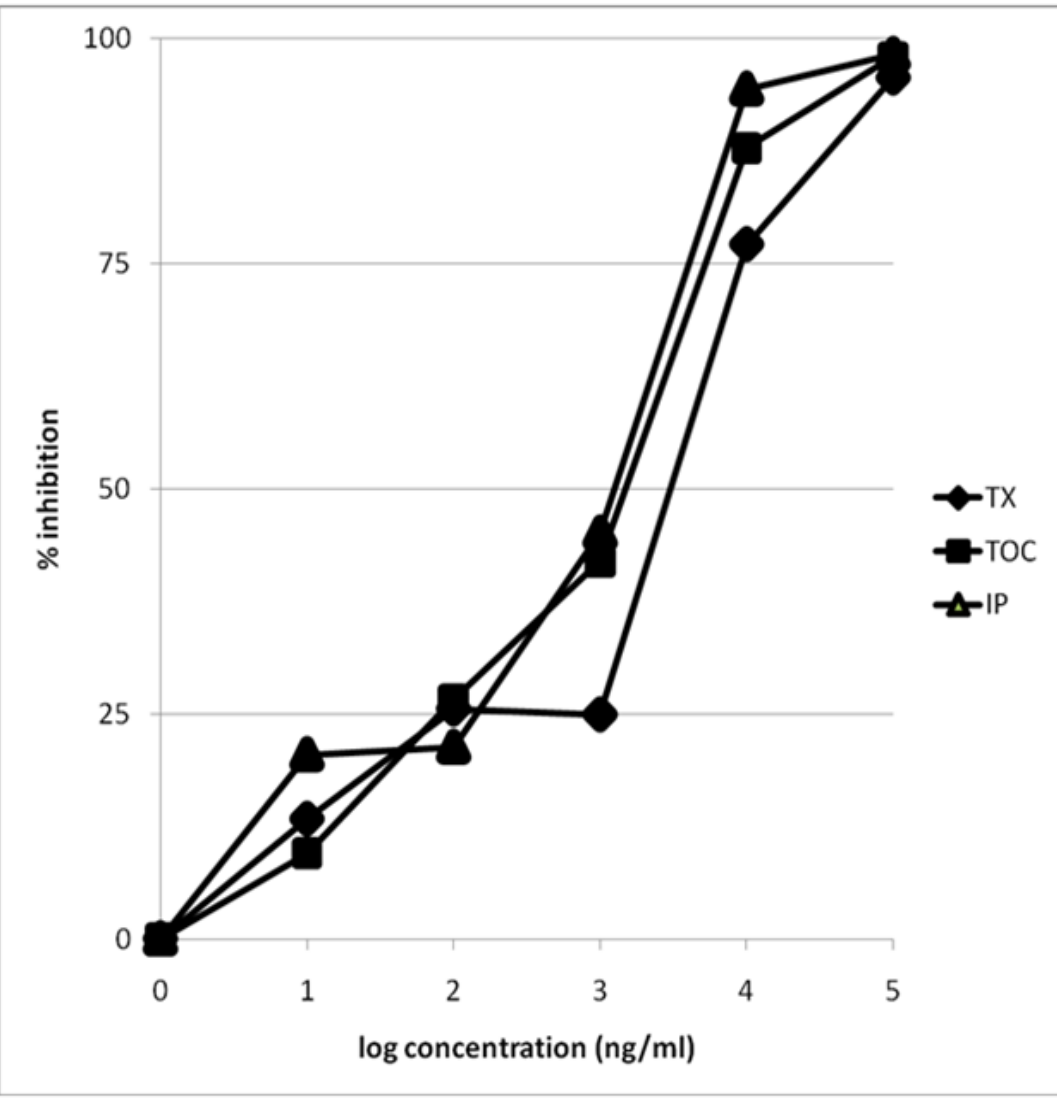

Figure 3: The induction of lipid peroxidation, as monitored by malondialdehyde (MDA) formation at Ex $515 \mathrm{~nm}$, Em $553 \mathrm{~nm}$, by the addition of $3 \mathrm{mM}$ tert-butyl hydroperoxide to rat liver microsomes for $30 \mathrm{~min}$ with Trolox, $\alpha$-tocopherol acetate and Intsia palembanica. Values are means $\pm \operatorname{SD}(n=3)$.

TX: Trolox, TOC: $\alpha$-tocopherol acetate, IP: Intsia palembanica fraction. 
Newly developed xanthine oxidase inhibitors have been highly searched to replace the currently used allopurinol which is used for gout treatment despite its severe adverse effects. Allopurinol is a xanthine oxidase inhibitor applicable exclusively to treat chronic gout and conditions related to hyperuricemia Tan et al., [34]. Many studies have been conducted on plant extracts for a higher therapeutic activity and fewer side effects. It has been reported that crude extracts causing more than $50 \%$ xanthine oxidase inhibition at a test concentration of $100 \mu \mathrm{g} / \mathrm{ml}$ are justified for further investigation Sweeney et al. From the experiment, I. palembanica extract exhibited high inhibition activity with an $\mathrm{IC}_{50}$ of $6.3 \pm 2.5 \mu \mathrm{g} /$ $\mathrm{ml}, 10$ times more potent than the one proposed by Sweeney et al., Tan et al. suggested that most of the natural xanthine oxidase inhibitors present in the active extracts may be polyphenols. I. palembanica extract has been found to contain polyphenol substances [9] and the bark and leaves of I. palembanica were traditionally used in the treatment of rheumatoid, diarrhoea and urinary problems (Soerionegara \& Lemmens, 1993; Soon-Leong et al. 2002). Our study also has shown the presence of six polyphenols. This further support the result obtained from the XOI assay as it is traditionally used to treat inflammation. I. palembanica extract had potent inhibitory effect on the hydroperoxide-initiated lipid peroxidation in liver microsomes as compared to $\alpha$-tocopherol acetate or trolox (Figure 3). The $\mathrm{IC}_{50}$ values of I. palembanica, $\alpha$-tocopherol acetate and trolox were 1.26, 1.58 and $3.98 \mu \mathrm{g} / \mathrm{mL}$, respectively. I. palembanica extract showed a maximum inhibition at $98.2 \%$. Trolox and $\alpha$-tocopherol acetate reached a plateau at $95.6 \%$ and $97.2 \%$, respectively. TBARS production of microsomal fractions depended on the amount of tissue, the time of incubation, the concentration of tert-butylhydroperoxide and the presence of antioxidants, if any. TBARS is a good index of lipid peroxidation in rat and rabbit microsomes when compared with the production of hydroperoxides (Tien \& Aust 1986) (Figure 3).

This study has demonstrated that I. palembanica extract possessed antioxidant and free-radical scavenging activity. However, it is said that an antioxidant via chelation of $\mathrm{Fe}^{2+}$ is a more significant mechanism in preventing lipid peroxidation than direct free radical scavenging [35]. Certainly, the ethyl cetate extract had the ability to inhibit lipid peroxidation and xanthine oxidase, chelate $\mathrm{Fe}^{2+}$ and/or scavenge DPPH${ }^{*}$. Then again, the extract showed different behaviour in different assays, probably due to the different mechanisms involved. It is inappropriate to use only one method to assess antioxidant capability of a sample because the antioxidant activity measured by an individual assay exhibits only the chemical reactivity under specific conditions applied in that particular assay $[36,37]$. Oxidative stress in cells can be reduced by antioxidants and this notion is useful in treating many human diseases, including cancer, cardiovascular diseases and inflammatory diseases (Krishnaiah et al, 2011). Dietary polyphenols play a role in the prevention of degenerative diseases, particularly cardiovascular diseases and cancers and has been considerably developed for the past 15 years Krishnaiah et al. [38]. Although the antioxidant properties has been extensively studied, the mechanism of actions of the polyphenols are past the modulation of oxidative stress [5]. Several studies have investigated the relationship between plant products and their antioxidant activities. Positive correlations can be seen in a lot of studies between the phenolic content and the antioxidant activities exhibited. High antioxidant capacities may be contributed by unidentified compounds and their synergistic interactions with other polyphenols present in the plant products leading to health improvement and disease prevention [39] Valentova et al. The aromatic rings in the polyphenol structure with one or more hydroxyl groups and other functional groups may be the contributing factor (Rice-Evans et al. 1996). These structures are able to scavenge ROS (Halliwell, 1999; 2000), inhibit lipid peroxidation (Jovanovic et al., 1994; Fraga et al., 1987) and chelate metal ions (Terao et al., 1994; Halliwell, 1995) depending on the number and the location of the hydroxyl groups. Polyphenols inhibit oxidation processes via: (i) chelation of metal ions by the O-hydroxy phenolic structure; (ii) scavenging of alkoxyl lipid radical and peroxyl radical by terminating chain reaction, or (iii) regeneration of $\alpha$-tocopherol through reduction of $\alpha$-tocopheroxyl radical (Rice-Evans, 1995).

The need to improve human health and quality of life gave rise to studies on the biological activities of polyphenols, in vivo and in vitro. Polyphenols present in red wine and tea have been shown to have potent antioxidant characteristics El Attar and Virji, [40]. Tea is a rich source of polyphenols, more potent than other vegetables and fruits that could inhibit LDL oxidation caused by ROS which can lead to atherogenesis Ishikawa et al., Scalbert et al., [41,42]. This may be due to the catechol moiety existed in the polyphenol compound in tea (o-hydroxy or o-trihydroxypenyl rings) Ishikawa et al., Javonovic et al., [43]. Medicinal plants have played an important role in the culture of healing human and livestock diseases, traditionally. From these claims of almost $80 \%$ from the world's population in developing countries, many investigations have been carried out to prove scientifically the efficacies of these plants which have consistently been an important source of therapeutic agents. Hence, at present, about $25-30 \%$ of all drugs available as source of therapeutics are derived from plants, microbes and animals or are natural product derivatives [15,44,45]. Over 490 medicinal plant species from Fabaceae (second largest family of medicinal plants) nhave been used as traditional medicines [46]. Some ethnomedicinal plants from the family Fabaceae have been identified for the use of treating diabetes, diarrhea, dysentery, fever, arthritis, goitre, skin disease and many others in India. The root paste of Flemingia macrophylla was reported to be applied on affected areas for people suffering arthritis and the stem bark decoction for treating fever (Tirkey, 2006). The same plant was also claimed to have anti-inflammatory and antidiabetic activities by the Taiwanese and have demonstrated potent anti-hyperglycemic activity [47]. The flavonoids from Flemingia macrophylla also had neuroprotective activity against Alzheimer's disease $[48,49]$. The tubers of Hydnophytum formicarum Jack from the Rubiaceae family has been used traditionally to treat hepatitis, rheumatism and diarrhea in South East Asia [50-52]. The ethyl acetate extract 
of this tuber demonstrated high antimicrobial and antioxidant activities due to the presence of phenolic compounds such as isoliquiritigenin, protocatechualdehyde, butin and butein [53].

Therefore, it is strongly suggested that the polyphenols in the ethyl acetate fraction of I. palembanica are protecting cells against any damage induced by oxidizing agents such as $\mathrm{H}_{2} \mathrm{O}_{2}$ and metal ions (ferrous ions). Damage done by ROS and transition metal ions could influence the plasma thiol level, antioxidant enzyme activity, protein carbonyl content, and fluidity of erythrocyte membrane $[54,55]$. The ethyl acetate extract of I. palembanica was able to scavenge DPPH• and t-Bu00* Number of hydroxyl groups and the glycosylation process of the polyphenol structure and the ability to chelate $\mathrm{Fe}^{2+}$ contributed to the inhibition [55], Halliwell and Gutteridge, Rice-Evans et al. The ability of I. palembanica extract to inhibit TBARS generation seems to be related to their ability of scavenging lipid radicals in rat liver microsomes. Dietary plant polyphenols have been shown to modulate lipid and carbohydrate metabolism, alleviate insulin resistance and hyperglycemia. These polyphenols can also improve oxidative stress and stress-sensitive signallig pathways and inflammatory processes [56]. These findings proved that the presence of polyphenols in I. palembanica have potent antioxidant activities and react through the radical scavenging mechanism more than the chelation of $\mathrm{Fe}^{2+}$. This is shown by the identification of six polyphenol compounds from the ethyl acetate extract such robinetinidol, dihydrorobinetin, two isomers of ampelopsin [(2R, 3S)- and $(2 R, 3 R)$-ampelopsin], robinetin and myricetin. Furthermore, a study done by [57] have confirmed a strong radical scavenger in $\mathrm{ABTS}^{+}$assays: $34.11 \pm 0.02$ $\mathrm{mM}$ Trolox equivalents per $\mathrm{g}$ of dry extract in the extract of merbau wood [57]. Hence I. palembanica may be a powerful free radical inhibitor or scavenger, as well as a primary antioxidant that reacts with free radicals, which may limit free radical damage occurring in the human body [58-63].

\section{Conclusion}

The results presented here with Intsia palembanica extract suggested that the potentiality to be successfully used in human health in the prevention of diseases involving free radical and oxidative damage are quite promising. These findings should be taken into consideration to develop protective antioxidants that may have significant applications in fighting against human diseases caused by free radicals.

\section{Acknowledgement}

We would like to express our gratitude to Nor Azrina Azmi and Laila Mehat for their assistance. This work was financially supported by IRPA grant 06-02-02-0140 and Mizaton Hazizul Hasan is a recipient of a National Science Fellowship grant. We are indebted to Ministry of Science, Technology and Innovation, Malaysia for their contributions.

\section{Conflict of Interest}

No conflict of interest.

\section{References}

1. Cheung F (2011) TCM: Made in China. Nature 480 (7378): S82-S83.

2. (1994) Pharmaceuticals from plants: great potential, few funds. Lancet 343(8912): 1513-1515

3. Setzer MC, Setzer WN, Jackes BR, Gentry GA, Moriarity DM (2001) Plants from Paluma, North Queensland, Australia. Pharm Biol 39 (1): 67-78.

4. Scalbert A, Manach M, Morand C, Rémésy C, Jiménez L (2005a) Dietary polyphenols and the prevention of diseases. Crit Rev Food Sci 45(4): 287-306.

5. Scalbert A, Johnson IA, Mike Saltmarsh M (2005) Polyphenols: antioxidants and beyond. Am J Clin Nutr 81(1): 215S-217S.

6. Pandey KB, Rizvi SI (2009) Plant polyphenols as dietary antioxidants in human health and disease. Oxid. Med Cell Longev 2(5): 270-278.

7. Vauzour D, Rodriguez Mateos A, Corona G, Oruna Concha MJ, Spencer JP (2010) Polyphenols and human health: prevention of disease and mechanisms of action. Nutrients 2(11): 1106-1131.

8. Pietta PG (2000) Flavonoids as antioxidants. J Nat Prod 63(7): 10351042.

9. Hillis WE, Yazaki Y (1973) Polyphenols of Intsia heartwoods. Phytochemistry 12(10): 2491-2495.

10. Whitmore TC (1972) Leguminosae. Tree flora of Malaya, Forest Depart, Ministry of Agriculture and Land Malaysia, Longman: Malaysia.

11. Batubara I, Darusman T, Rahminiwati, M (2010) Potency of Indonesian medicinal plants as tyrosinase inhibitor and antioxidant agent. J Biol Sci 10(2): 138-144

12. Quattrocchi U (2012) CRC World Dictionary of Medicinal and Poisonous Plants: Common Names, Scientific Names, Eponyms, Synonyms, and Etymology. CRC Press 2079-2080.

13. Otshudi AL, Foriers A, Vercruysse A, Van Zeebroeck A, Lauwers S (2000) In vitro antimicrobial activity of six medicinal plants traditionally used for the treatment of dysentery and diarrhoea in Democratic Republic of Congo (DRC). Phytomedicine 7(2): 167-172.

14. Hu F, Lu R, Huang B, Liang M (2004) Free radical scavenging activity of extracts prepared from fresh leaves of selected Chinese medicinal plants. Fitoterapia 75(1): 14-23.

15. Ahmad I, Aqil F, Owais M (2006) Modern phytomedicine: turning medical plants into drugs.

16. De Sousa Araujo TA, Alencar NL, de Amorim EL, De Albuquerque UP (2008) A new approach to study medicinal plants with tannins and flavonoids contents from the local knowledge. J Ethnopharmacol 120(1): 72-80.

17. Saroja M, Santhi R, Annapoorani S (2012) Wound healing activity of flavonoid fraction of Cynodon dactylon in Swiss albino mice. Int Res J Pharm 3(2): 230-231.

18. Pietta P, Simonetti P, Mauri P (1998) Antioxidant activity of selected medicinal plants. J Agric Food Chem 46(11): 4487-4490.

19. Auddy B, Ferreira M, Blasina F, Lafon L, Arredondo F, et al. (2003) Screening of antioxidant activity of three Indian medicinal plants, traditionally used for the management of neurodegenerative diseases. J Ethnopharmacol 84(2-3): 131-138.

20. Ivanova D, Gerova D, Chervenkov T, Yankova T (2005) Polyphenols and antioxidant capacity of Bulgarian medicinal plants. J Ethnopharmacol 96(1-2): 145-150

21. Djeridane A, Yousfi M, Nadjemi B, Boutassouna D, Stocker P, et al. (2006) Antioxidant activity of some Algerian medicinal plants extracts containing phenolic compounds. Food Chem 97(4): 654-660.

22. Surveswaran S, Cai YZ, Corke H, Sun M (2007) Systematic evaluation of natural phenolic antioxidants from Indian medicinal plants. Food Chem 102(3): 938-953.

23. Barros L, Oliveira S, Carvalho AM, Ferreira I (2010) In vitro antioxidant properties and characterization in nutrients and phytochemicals of 
six medicinal plants from the Portuguese folk medicine. Ind Crop Prod 32(3): 572-579.

24. Le NH, Malterud KE, Diallo D, Paulsen BS, Nergard CS, et al. (2012) Bioactive polyphenols in Ximenia americana and the traditional use among Malian healers. J Ethnopharmacol 139(3): 858-862.

25. Shen CC, Chang YS, Ho LK (1993) Nuclear magnetic resonance studies of 5,7-dihydroxyflavonoids. Phytochemistry 34(3): 843-845.

26. Atsumi T, Iwakura I, Kashiwagi Y, Fujisawa S, Ueha T (1999) Free radical scavenging activity in the non-enzymatic fraction of human saliva: a simple DPPH assay showing the effect of physical exercise. Antioxid Redox Signal 1(4): 537-546.

27. Decker EA, Welch B (1990) Role of ferritin as a lipid oxidation catalyst in muscle food. J Agri Food Chem 38: 674-677.

28. Bird RP, Draper HH (1984) Comparative studies on different methods of malonaldehyde determination. Methods Enzymol 105: 299-305.

29. Kou, Chen (2012) Pharmacological potential of ampelopsin in Rattan tea. FSHW 1(1): 14-18.

30. Li Y, Ding Y (2012) Minireview: Therapeutic potential of myricetin in diabetes mellitus. FSHW 1(1): 19-25.

31. Semwal DK, Semwal RB, Combrinck S, Viljoen A (2016) Myricetin: A Dietary Molecule with Diverse Biological Activities. Nutrients, 8(2): 90.

32. Gulcin I, Buyukokuroglu ME, Oktay M, Kufrevioglu OI (2003) Antioxidant and analgesic activities of turpentine of Pinus nigra Arn. Subsp. Pallsiana (Lamb.) Holmboe. J Ethnopharmacol 86(1): 51-58.

33. Tanaka M, Kuei CW, Nagashima Y, Taguchi T (1998) Application of antioxidative maillrad reaction products from histidine and glucose to sardine products. Nippon Suisan Gakkaishi 54(8): 1409-1414.

34. Pacher P, Nivorozhkin A, Szabo C (2006) Therapeutic Effects of Xanthine Oxidase Inhibitors: Renaissance Half a Century after the Discovery of Allopurinol. Pharmacol Rev 58(1): 87-114.

35. Goncalves S, Diogo Gomes, Patricia Costa, Anabela Romano (2013) The phenolic content and antioxidant activity of infusions from Mediterranean medicinal plants. Ind Crop Prod 43: 465-471.

36. Huang D, Ou B, Prior RL (2005) The chemistry behind antioxidant capacity assays J Agric Food Chem 53(6): 1841-1856.

37. Carocho M, Ferreira C F R (2013) A review on antioxidants, prooxidants and related controversy: Natural and synthetic compounds, screening and analysis methodologies and future perspectives. Food Chem Toxicol 51: $15-25$.

38. Daniele Del Rio, Ana Rodriguez Mateos, Jeremy P E Spencer, Massimiliano Tognolini, Gina Borges, et at. (2013) Dietary (Poly)phenolics in Human Health: Structures, Bioavailability, and Evidence of Protective Effects Against Chronic Diseases. Antioxid Redox Signal 18(14): 1818-1892.

39. Liu RH (2003) Health benefits of fruit and vegetables are from additive and synergistic combinations of phytochemicals. Am J Clin Nutr 78(3): 517S-520S.

40. Yang CS, Chung JY, Yang G, Chhabra SK, Lee MJ (2000) Tea and tea polyphenols in cancer prevention. J Nutr 130: 472S-478S.

41. Heim K, Tagliaferro A, Bobilya D (2002) Flavonoid antioxidants: Chemistry, metabolism and structure-activity relationships. J Nutr Biochem 13(10): 572-584.

42. Sesso HD, Gaziano JM, Buring JE, Hennekens CH (1999) Coffee and tea intake and the risk of myocardial infarction. Am J Epidemiol 149(2): 162-167.

43. Spencer JP (2003) Metabolism of tea flavonoids in the gastrointestinal tract. J Nutr 133(10): 3255S-3261S.

44. Calixto JB (2005) Twenty-five years of research on medicinal plants in Latin America: A personal view. J Ethnopharmacol 100(1-2): 131-134.

45. Lahlou M (2013) The Success of Natural Products in Drug Discovery. Pharmacol Pharm 4: 17-31.
46. Gao T, Yao H, Song J, Liu C, Zhu Y, et al. (2010) Identification of medicinal plants in the family Fabaceae using a potential DNA barcode ITS2. J Ethnopharmacol 130(1): 116-121.

47. Syiem D, Khup PZ (2007) Evaluation of Flemingia macrophylla L., a traditionally used plant of the north eastern region of India for hypoglycemic and anti-hyperglycemic effect on mice. Pharmacologyonline 2: 355-366.

48. Shiao YJ, Wang CN, Wang WY, Lin YL (2005) Neuroprotective flavonoids from Flemingia macrophylla. Planta Medica 71(9): 835-840.

49. Lin YL, Tsay HJ, Liao YF, Wu MF, Wang CN, et al. (2012) The Components of Flemingia macrophylla Attenuate Amyloid $\beta$-Protein Accumulation by Regulating Amyloid $\beta$-Protein Metabolic Pathway. Evid Based Complement Alternat Med 2012: 795843.

50. Ueda JY, Tezuka Y, Banskota AH, Tran QL, Tran QK, et al. (2002) Antiproliferative activity of Vietnamese medicinal plants. Biol Pharm Bull 25(6): 753-760.

51. Nguyen MT, Awale S, Tezuka Y, Tran QL, Watanabe H, et al. (2004) Xanthine oxidase inhibitory activity of Vietnamese medicinal plants. Biol Pharm Bull 27(9): 1414-1421.

52. Abdullah H, Pihie A, Hohmann J, Molnar J (2010) A natural compound from Hydnophytum formicarium induces apoptosis of MCF-7 cells via up-regulation of Bax. Can Cell Int 10(1): 10-14.

53. Prachayasittikul S, Buraparuangsang $P$, Worachartcheewan A, Isarankura $\mathrm{Na} \mathrm{AC,} \mathrm{Ruchirawat} \mathrm{S,} \mathrm{et} \mathrm{al.} \mathrm{2008.} \mathrm{Antimicrobial} \mathrm{and} \mathrm{Antioxidative}$ Activities of Bioactive Constituents from Hydnophytum formicarum Jack. Molecules 13(4): 904-921.

54. Yelinova V, Glazachev Y, Khramtsov V, Kudryashova L, Rykova V, et al. (1996) Studies of human and rat blood under oxidative stress: changes in plasma thiol level, antioxidant enzyme activity, protein carbonyl content, and fluidity of erythrocyte membrane. Biochem Biophys Res Commun 221(2): 300-303.

55. Swaran JS Flora (2009) Structural, chemical and biological aspects of antioxidants for strategies against metal and metalloid exposure. Oxid Med Cell Longev 2(4): 191-206.

56. Bahadoran Z, Mirmiran P, Azizi F (2013) Dietary polyphenols as potential nutraceuticals in management of diabetes: a review. J Diabetes Metab Disord 12(1): 12-43.

57. Bartakova M, Dvorackova E, Chromcova L, Hrdlicka P (2019) Simple phenols in tropical woods determined by UHPLC-PDA and their antioxidant capacities: an experimental design for Randall extraction using environmentally friendly solvents. J For Res 67.

58. SJ Hardwick, Adam A, LL Smith, GM Cohen (1990) A novel lung slice system with compromised antioxidant defenses. Environ Health Perspect 85: 129-133.

59. Hardwick SJ, Adam A, Smith LL, Cohen GM (1990) Potentiation of the cell-specific toxicity of paraquat by 1,3-bis (2-chloroethyl)-1-nitrosourea (BCNU): Implications for the heterogeneous cellular distribution of glutathione (GSH) in rat lung. Biochem Pharmacol 39(3): 581-589.

60. Meister A (1995) Glutathione biosynthesis and its inhibition. Methods in Enzymology 252: 26-30.

61. Palozza P, Moualla S, Krinsky NI (1992) Effects of beta-carotene and alpha-tocopherol on radical-initiated peroxidation of microsomes. Free Radic Biol Med 13: 127-136.

62. Umamaheswari M, AsokKumar K, Somasundaram A, Sivashanmugam S, Subhadradevi V, et al. (2007) Xanthine oxidase inhibitory activity of some Indian medical plants. J Ethnopharm 109(3): 547-551

63. Weber JFF, Ibtisam AW, Vahitha AS, Marzuki A, Adam A, et al. (2000) Proceedings of the 15th Seminar of the Malaysian Natural Prod. Soc Penang. 